\title{
THE MEMBRANE PROPERTIES, AND EXCITATION- CONTRACTION COUPLING OF M. DIGASTRICUS OF THE GUINEA PIG
}

\author{
Teruyoshi OHвU \\ Department of Physiology, Faculty of Dentistry, Kyushu University, Fukuoka 812, Japan
}

Summary Electrical and mechanical properties of $M$. digastricus of the guinea pig were investigated by the microelectrode and strain gauge methods.

1) The mean diameter of the muscle fibres was $45.9 \mu$. The triad structures appeared in the region of the A-I junction, i.e. two triad structures appeared within one sarcomere.

2) The resting membrane potential was $-81.9 \mathrm{mV}$. One type of muscle fiber had a length constant $0.72 \mathrm{~mm}$, specific membrane resistance 1,300 $\Omega \mathrm{cm}^{2}$, internal resistance of the muscle $290 \Omega \mathrm{cm}$, whereas the other type of muscle fiber gave values of $0.72 \mathrm{~mm}, 330 \Omega \mathrm{cm}^{2}$ and $73 \Omega \mathrm{cm}$ respectively. 3) The changes of the membrane potential in various external concentrations of $\mathrm{K}$ ion were observed. The maximum slope of membrane potential change for tenfold change of $\mathrm{K}$ ion was $54 \mathrm{mV}$ in solutions prepared so that $[\mathrm{K}]_{o} \times[\mathrm{Cl}]_{o}=$ constant.

4) Spikes could be elicited by electrical stimulation. The overshoot was $15 \mathrm{mV}$ and the maximum rates of rise and fall were $340 \mathrm{~V} / \mathrm{sec}$ and $134 \mathrm{~V} / \mathrm{sec}$ respectively.

5) The conduction velocity of excitation was $2.9 \mathrm{~m} / \mathrm{sec}$, the time constant of foot of the propagated spike was $0.1 \mathrm{msec}$ and the chronaxie was $0.39 \mathrm{msec}$.

6) The time constant of the membrane was calculated by various methods based on the cable theory, and the calculated values of the time constant were discussed in terms of the activity and structure of the muscle.

7) Although two types of the muscle fibre were distinguishable from their electrical properties, these two types could not be classified, from the results of this study, into fast and slow (or twitch and tonic) muscles.

8) Electrical stimulation and excess $\mathrm{K}$ ion evoked tension development, the threshold potential necessary to produce tension development being $-35 \mathrm{mV}$.

Received for publication November 29, 1971

大部彰義 
9) Caffeine and thymol modified the mechanical responses of the muscle. Caffeine enhanced the amplitude and prolonged the time taken to reach the peak of the contraction. Thymol, on the other hand, prolonged the relaxation time. Presumably caffeine increased the release of $\mathrm{Ca}$ ion and thymol inhibited the reabsorption of $\mathrm{Ca}$ ion by the reticulum.

10) The mechanical responses of $M$. digastricus were compared with those of M. semitendinosus.

The membrane properties of mammalian striated muscle have been studied by many investigators in normal and in denervated conditions, and also the electrical and mechanical properties of the tonic (slow) and phasic (twitch, fast) muscle fibres have been compared (KIYOHARA et al., 1967; BoYD et al., 1959; Desmedt, 1959; Albuquerque and TheslefF, 1968). General features of the mammalian striated muscle can be pointed out as follows. (i) Both the slow and fast muscle membranes have nearly the same values for the characteristic constants of the membrane. (ii) The specific membrane resistance, the specific membrane capacitance and the space constant of the membrane are much smaller than those observed in frog twitch muscle fibres. (iii) The values of the characteristic constants of mammalian striated muscle are much closer to those observed in the frog slow muscle fibres. (iv) The resting membrane potentials of the mammalian striated muscles are lower than those observed in the frog twitch muscle fibres (Katz, 1948; Adrian and Peachey, 1965; Stefani and Steinbach, 1969).

Occlusion and mastication result from joint and masticatory muscle activities, and several muscles contribute to the opening and closing of the mouth. Electromyographic activities of the masticatory muscles have been extensively investigated by many workers (see the reviews of ANDERSON, 1968; KAWAMURA and FuJIMOTo, 1958). However, no study has been made on the passive membrane characteristics of the masticatory muscle tissues.

The present experiments were carried out to investigate the electrical properties and excitation-contraction coupling of $M$. digastricus, the contraction of which causes the mouth to open. The results were discussed in comparison with those of other mammalian striated muscles.

\section{METHODS}

Guinea pigs weighing $250-350 \mathrm{~g}$ were stunned and bled. The skin of the ventral side of the neck was dissected in a longitudinal direction. When the mandibular and thyroid glands were removed, $M$. digastricus appeared just below. The muscle tissue was ablated from Os. mandibularis and from the intermediate tendon where it was connected to corpus ossis hyoideium. Finally, the tissue was excised at the connection of processus styloides with venter posterior of $M$. 
digastricus. The connective tissue was carefully dissected from the muscle, placed under the optical microscope in Krebs solution at $20-22^{\circ} \mathrm{C}$. The length of the muscle tissue was about $30 \mathrm{~mm}$ and its weight was $180-250 \mathrm{mg}$. To compare the mechanical activity of $M$. digastricus with other skeletal muscle, $M$. semitendinosus was used. M. semitendinosus was excised from the same guinea pig. The muscles were mounted in an organ bath through which solution flowed continuously at a bath temperature of $25-30^{\circ} \mathrm{C}$, propelled by a thermostatically controlled pump.

The arrangement for stimulating the membrane and recording its properties was the partition stimulating method described by Katz (1948), ABE and TomITA (1968). The organ bath was divided into three chambers. The two outer chambers were perfused with Krebs solution and the middle chamber was perfused with sucrose solution. To record the electrical properties, microelectrodes (tip diameter of about $0.2 \mu$ and resistance $30-50 \mathrm{M} \Omega$ ) filled with $3 \mathrm{M} \mathrm{KCl}$ were used. Field stimulation of the tissue, for recording the conduction velocity of the excitation, was applied through a needle electrode coated with Araldite except for the tip (diameter $0.5 \mathrm{~mm}$ ), and an indifferent electrode was placed at a distance of 2.0 $2.5 \mathrm{~cm}$ from the tissue in the organ bath.

In addition to measuring the passive properties of the membrane by a different method from the partition method, two microelectrodes were inserted into the same muscle fibre. One electrode was for application of the current and the other for recording the potential. The distance apart of the two electrodes was measured with the aid of a binocular microscope.

To stimulate the tissue to elicit contraction, multigrid electrodes were placed parallel to the tissue, on both sides of it. The two multigrid electrodes were $0.8 \mathrm{~cm}$ apart, and the length of the electrodes was $3.2 \mathrm{~mm}$, which was longer than the tissue itself. The tension development was measured by a strain gauge (Nihon Kohden Ltd.). One end of the tendon (venter posterior) was connected to the hook of the strain gauge by a thread.

A modified Krebs solution (described below as Krebs solution) of the following composition was used $(\mathrm{mm}): \mathrm{Na}^{+}, 137.4 ; \mathrm{K}^{+}, 5.9 ; \mathrm{Mg}^{++}, 1.2 ; \mathrm{Ca}^{++}, 2.5 ; \mathrm{Cl}^{-}$, 134.0; $\mathrm{HCO}_{3}^{-}, 15.5 ; \mathrm{H}_{2} \mathrm{PO}_{4}^{-}, 1.2$; glucose, 11.5 ; equilibrated with $97 \% \mathrm{O}_{2}+3 \%$ $\mathrm{CO}_{2}$. The $\mathrm{pH}$ of the solution was about 7.2. To observe the effects of different

Table 1. Ionic composition of solutions (mM).

\begin{tabular}{rlrrrrrr}
\hline \multicolumn{2}{c}{$[\mathrm{K}]_{0}$} & Normal & $2.5 \times$ & $5 \times$ & $10 \times$ & $15 \times$ & $20 \times$ \\
\hline Solution I & $\mathrm{K}$ & 5.9 & 14.8 & 29.5 & 59 & 88.5 & 118 \\
& $\mathrm{Na}$ & 137.4 & 128.6 & 113.8 & 84.3 & 54.8 & 25.3 \\
& $\mathrm{Cl}$ & 134.1 & 134.1 & 134.1 & 134.1 & 134.1 & 134.1 \\
\hline Solution II & $\mathrm{K}$ & 5.9 & 14.8 & 29.5 & 59 & 88.5 & 118 \\
& $\mathrm{Na}$ & 137.4 & 128.6 & 113.8 & 84.3 & 54.8 & 25.3 \\
& $\mathrm{Cl}$ & 134.1 & 54 & 27 & 13.4 & 8.9 & 6.7 \\
\hline
\end{tabular}


ionic environments on the tissue, solutions of various ionic composition were prepared. These are shown in Table 1. The concentrations of drugs (caffeine, thymol) are indicated in the results.

\section{RESULTS}

\section{Histological observations of $M$. digastricus}

The morphology of $M$. digastricus was investigated by the optical microscope and the electron microscope. The optical microscopy was carried out mainly to measure the diameters of the muscle fibre, following the fresh frozen section method. Figure 1 shows the histological arrangement of the muscle tissue. Figure

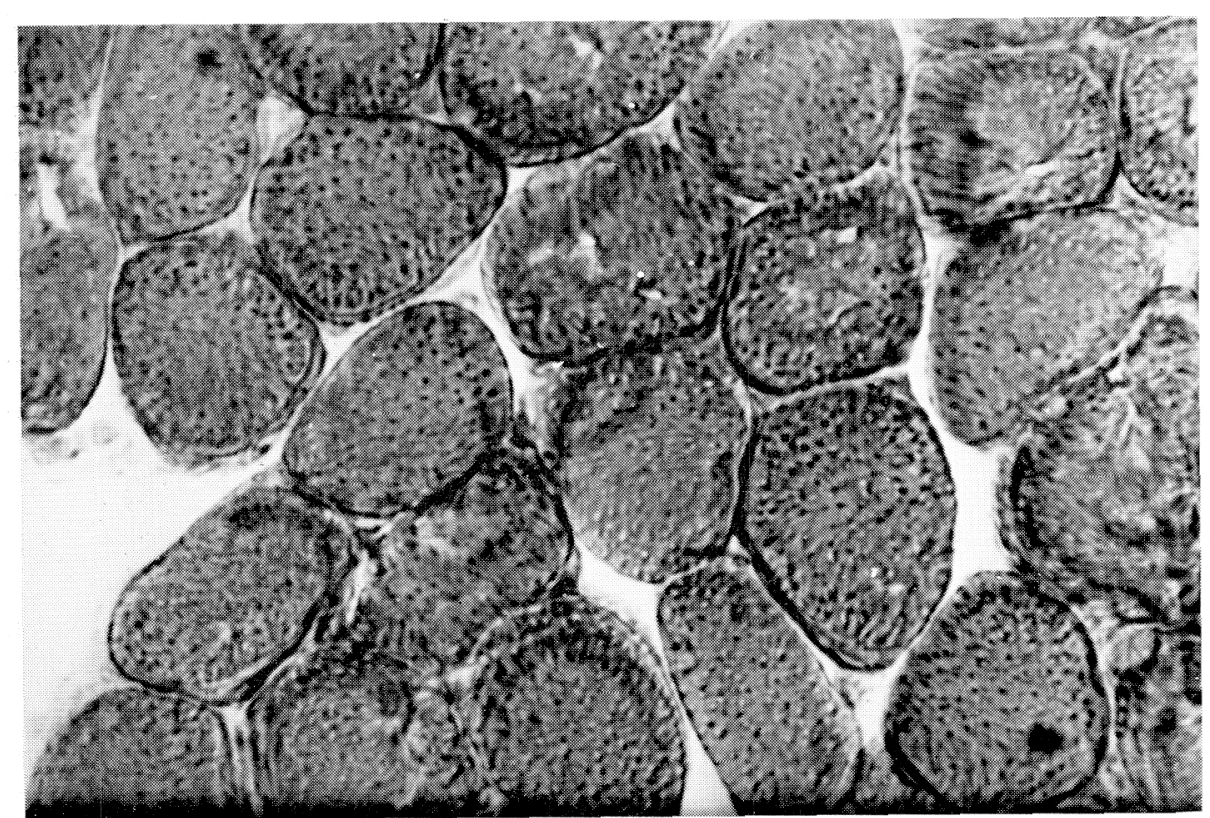

Fig. 1. Photomicrograph of $M$. digastricus prepared by the fresh frozen section method.

2 shows a histogram of the fibre diameters, which varied from $30 \mu$ to $65 \mu$, the mean value being $45.9 \mu(n=200)$. The extracellular space of the muscle tissue measured by this method was $16.3 \%$, but no adjustment was made for the small amount of muscle shrinkage due to the freeze drying method. The muscle tissue of $M$. digastricus is composed of two muscle bundles connected to a central tendon. The histological preparations were made solely from the muscle tissue and did not include the tendon.

Figure 3 shows electronmicrographs made from $M$. digastricus. Typical 


\section{M.digastricus}

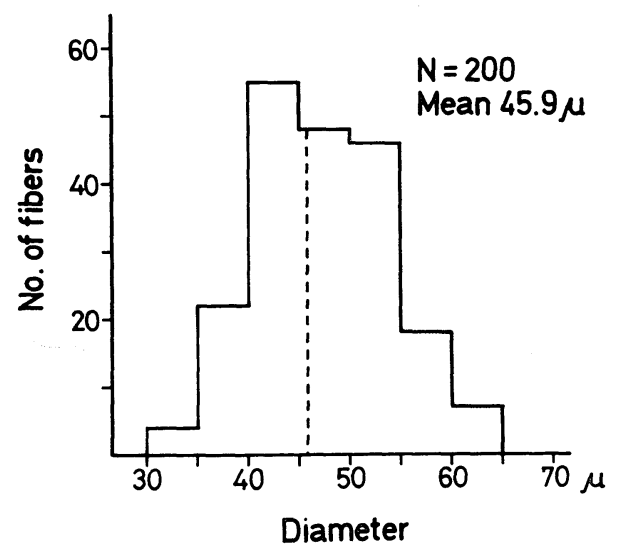

Fig. 2. Distribution of fibre diameter of $M$. digastricus. The histogram was calculated from photomicrographs of a muscle fibre prepared by the freeze drying method. Dotted line indicates the average diameter of the fibres.

features of the twitch muscle fibres can be observed, i.e. the length of the sarcomere was roughly $2.5 \mu$. The A and I bands were clearly observed between Z-lines, which appeared in zigzag orders. Regularly arranged tubular structures, a welldeveloped sarcoplasmic reticulum and the triad structure could be identified. The triad structures were found at the level of the A-I border between the Z-lines, i.e. two triad structures appeared within one sarcomere.

\section{Electrical properties of the muscle membrane}

Changes of the resting membrane potential in various ionic environments. The mean membrane potential of $M$. digastricus was $-81.9 \pm 5.8 \mathrm{mV}(n=170)$, measured at $30^{\circ} \mathrm{C}$. This value was higher than that observed for M. ext. dig. longus $(-72 \mathrm{mV})$ and $M$. soleus $(-71 \mathrm{mV})$ of the rat, measured at $25^{\circ} \mathrm{C}$. The fibre diameters of these two muscles were $21 \mu$ and $24 \mu$ respectively. The different values of the membrane potentials obtained from $M$. digastricus and the muscles of the rat might be a result of the different diameters of the muscle fibres (ALBUQUERQUE and THESLEFF, 1968).

The relationship between the membrane potential and the external K-concentration, $[\mathrm{K}]_{\mathrm{o}}$, was observed in two different conditions. The first series of solutions (solution I) were prepared with $[\mathrm{Na}]_{0}+[\mathrm{K}]_{\mathrm{o}}$ kept constant. Therefore, when $[\mathrm{K}]_{\text {o }}$ was increased, $[\mathrm{Na}]_{\text {。 }}$ was reduced isotonically in Krebs solution. The second solutions (solution II) were prepared with $[\mathrm{Na}]_{\mathrm{o}}+[\mathrm{K}]_{\mathrm{o}}$ kept constant, together with constant $[\mathrm{K}]_{\circ} \times[\mathrm{Cl}]_{o}$, i.e. the solution was prepared to maintain Donnan equilibrium between the extracellular and intracellular ionic concentrations. 

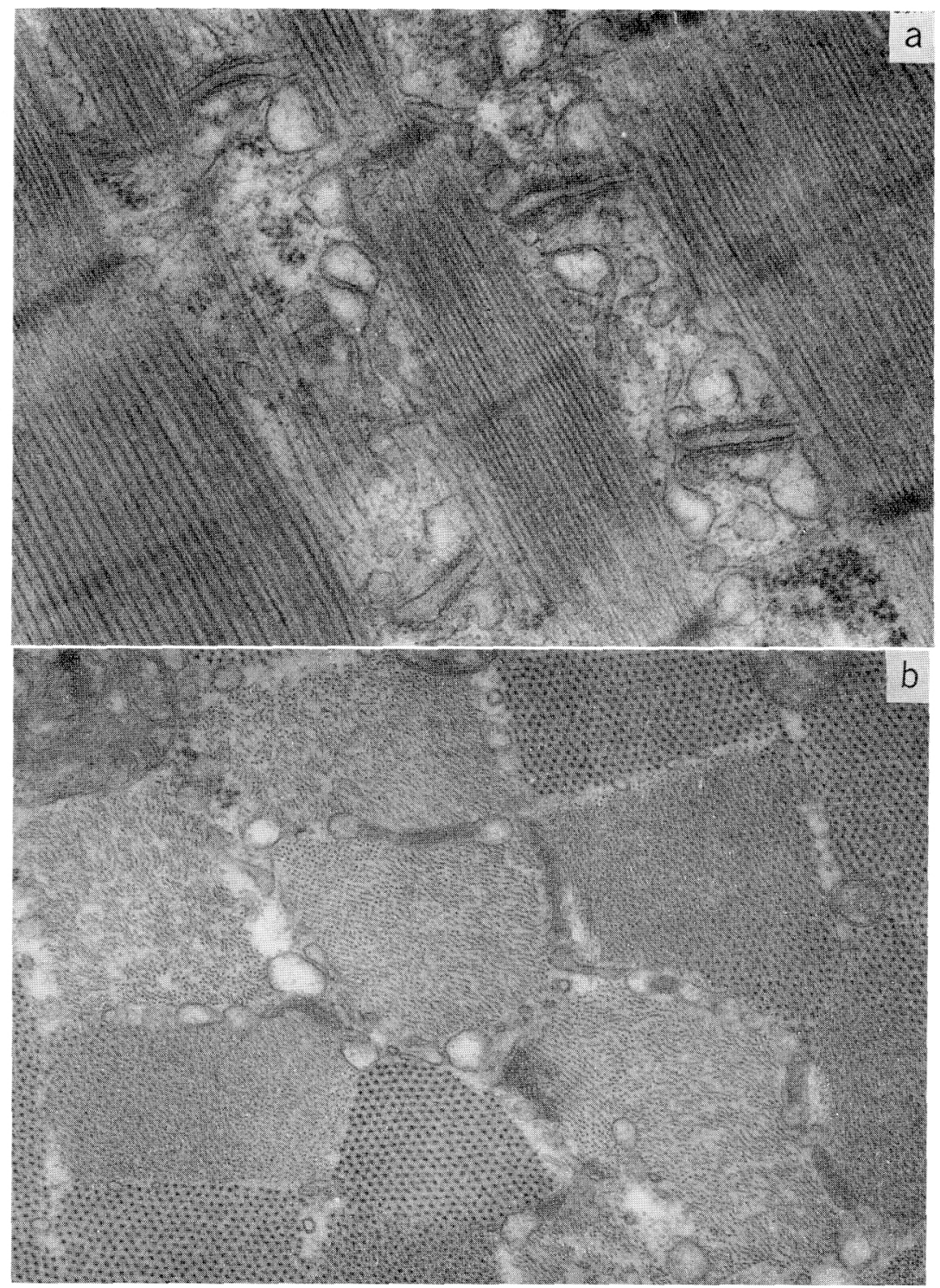

Fig. 3. Electron micrographs of $M$. digastricus.

a. longitudinal section $(\times 27,000)$

b. transverse section $(\times 25,000)$

Figure 4 shows the changes of the membrane potential in various $[\mathrm{K}]_{0}$ at $30^{\circ} \mathrm{C}$. In solution $\mathrm{I}$, the relationship between the membrane potential against $[\mathrm{K}]$ 。 plotted on a logarithmic scale was linear when $[\mathrm{K}]$ 。 was increased to more than twice the normal K-concentration of $5.9 \mathrm{~mm}$. The maximum slope of the membrane depo- 
larization against tenfold change of $[\mathrm{K}]$ 。 was $43 \mathrm{mV}$. When the solutions were prepared so as to satisfy the Donnan equation, i.e. solution II, a linear relation was also observed when the K-concentration was increased to more than twice the normal K-concentration, and the maximum slope of the membrane depolarization was $54 \mathrm{mV}$. The above two different solutions both depolarized the membrane, and the membrane potential in the steady state seems to be governed mainly by the distribution of $\mathrm{K}$ ion across the cell membrane. Furthermore,

\section{M. digastricus}

\section{Resting potential}

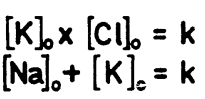

$$
[\mathrm{Na}]_{0}+[\mathrm{K}]_{0}=\mathrm{K}
$$
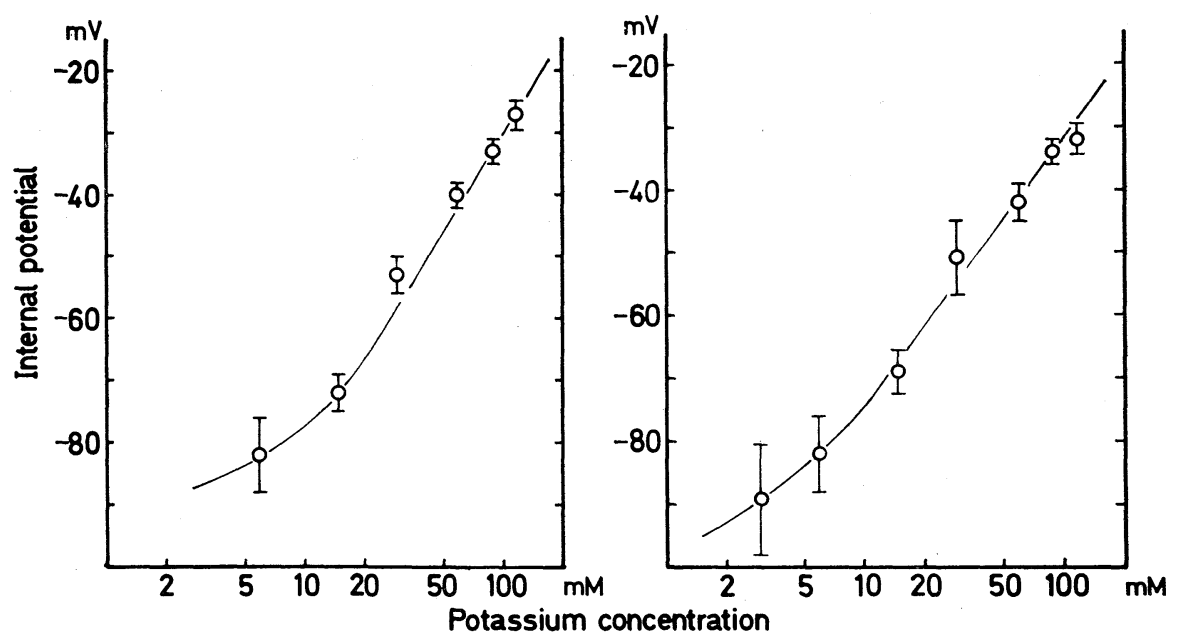

$T=30^{\circ} \mathrm{C}$

Fig. 4. Relationship between the resting potential of M. digastricus and external concentrations of potassium plotted by the logarithmic scale. Left: solution II. Right: solution I. Vertical bars indicate $2 \times$ S.D.

when the solutions were prepared so as to satisfy the Donnan equation, the maximum slope of the membrane depolarization roughly agreed with the changes of a K-electrode. Therefore, maximum slope of the depolarization of the the muscle membrane of $M$. digastricus was roughly $54 \mathrm{mV}$ per tenfold change of the external concentration of $\mathrm{K}$ ion, as predicted by the Boyle-Conway type of Donnan equilibrium (HodgKIN and Horowicz, 1959, 1960). The $\mathrm{Cl}$ ion distribution across the membrane seemed to be passive.

To confirm the above postulate, the effects on the membrane potential of $\mathrm{Cl}^{-}$replacement with $\mathrm{SCN}^{-}, \mathrm{NO}_{3}^{-}, \mathrm{Br}^{-}, \mathrm{SO}_{4}^{--}$and $\mathrm{C}_{6} \mathrm{H}_{5} \mathrm{SO}_{3}{ }^{-}$ion were observed. The 
results show that the membrane potential of $M$. digastricus did not change during replacement by foreign anions.

The discrepancy between the observed membrane potential and that predicted by the $\mathrm{K}^{+}$distribution might be due to permeability of $\mathrm{Na}$ ion in normal $[\mathrm{K}]_{0}$. From the constant field equation, the $P_{\mathrm{Na}} / P_{\mathrm{K}}$ value can be calculated from the following equation: $E_{m}=\left([\mathrm{K}]_{0}+\left(P_{\mathrm{Na}} / P_{\mathrm{K}}\right)[\mathrm{Na}]_{0} /[\mathrm{K}]_{\mathrm{i}}\right)$, if it is assumed that $\mathrm{Cl}$ distribution across the membrane is passive. When the relationship between the membrane potential and $[\mathrm{K}]$ 。 plotted on a logarithmic scale is extrapolated to $5.9 \mathrm{mM}[\mathrm{K}]_{\mathrm{o}}$, the $\mathrm{K}$-equilibrium potential can be obtained, assuming that at high $[\mathrm{K}]_{0}$ the slope of the membrane potential behaves as does the K-electrode. The $[\mathrm{K}]_{\mathrm{i}}$ value can be obtained from this value of the theoretical $\mathrm{K}$-equilibrium potential at $5.9 \mathrm{~mm}[\mathrm{~K}]_{0}$ using the Nernst equation. The $P_{\mathrm{Na}} / P_{\mathrm{K}}$ value so obtained was $0.02-0.03$.

\section{Passive electrical properties of the membrane}

Table 2 shows the various passive electrical parameters measured by the insertion of the two microelectrodes and also by the partition stimulating method.

Table 2. Electric membrane properties of M. digastricus.

Resting potential and spike

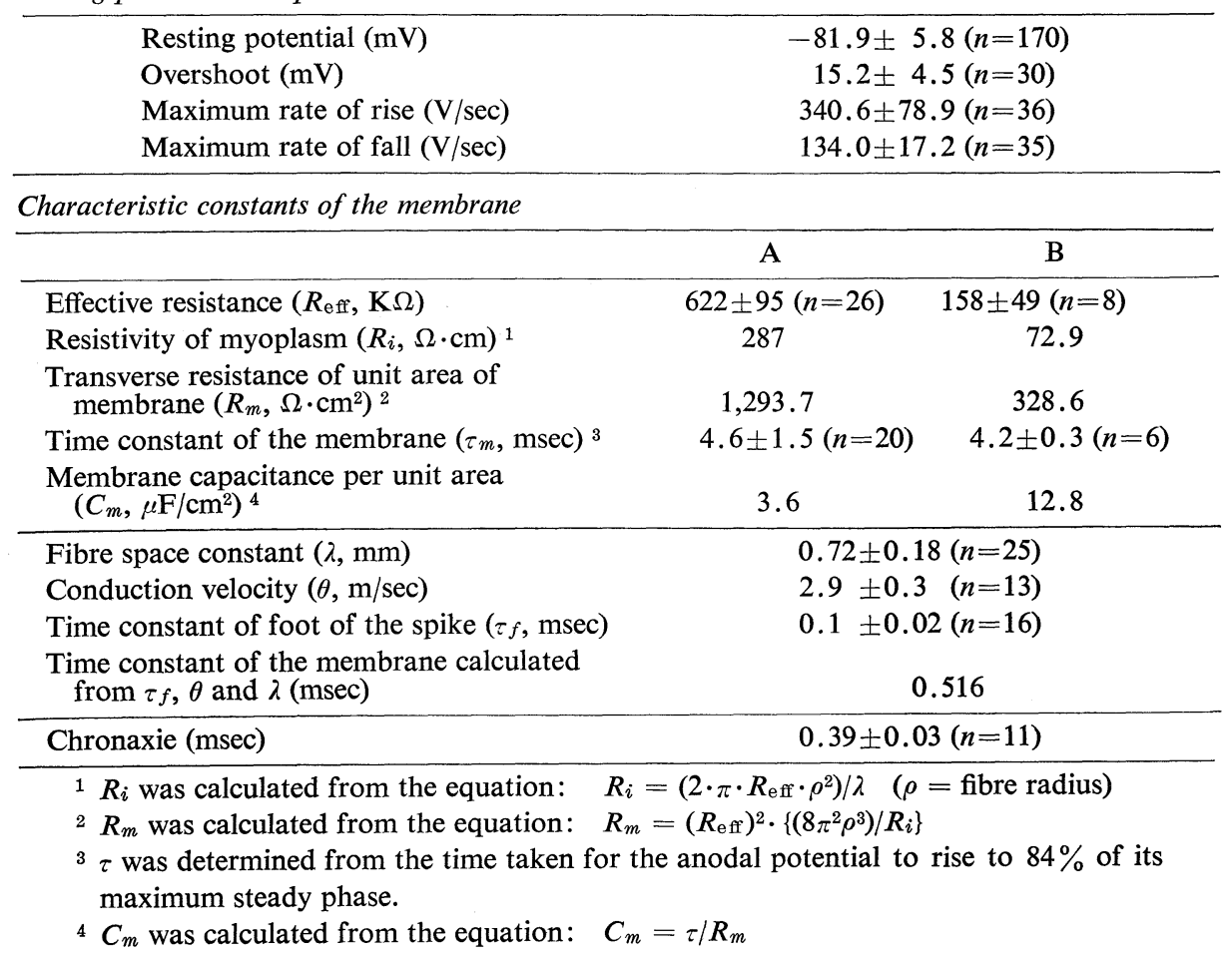


When weak inward and outward current pulses were applied to the tissue, an electrotonic potential could be evoked. Figure 5 shows examples of the current-voltage relationship of the membrane measured from $M$. digastricus. Muscle fibres giving two types of curve could be distinguished. Both types of muscle fibre had nearly the same value for the membrane potential and could generate spikes. One type of muscle fibre had a higher membrane resistance than the other, the linear relationship between the applied current intensity and the potential change varied widely, and rectification was small. The other type of muscle fibre with the lower membrane resistance showed marked rectification of the membrane.

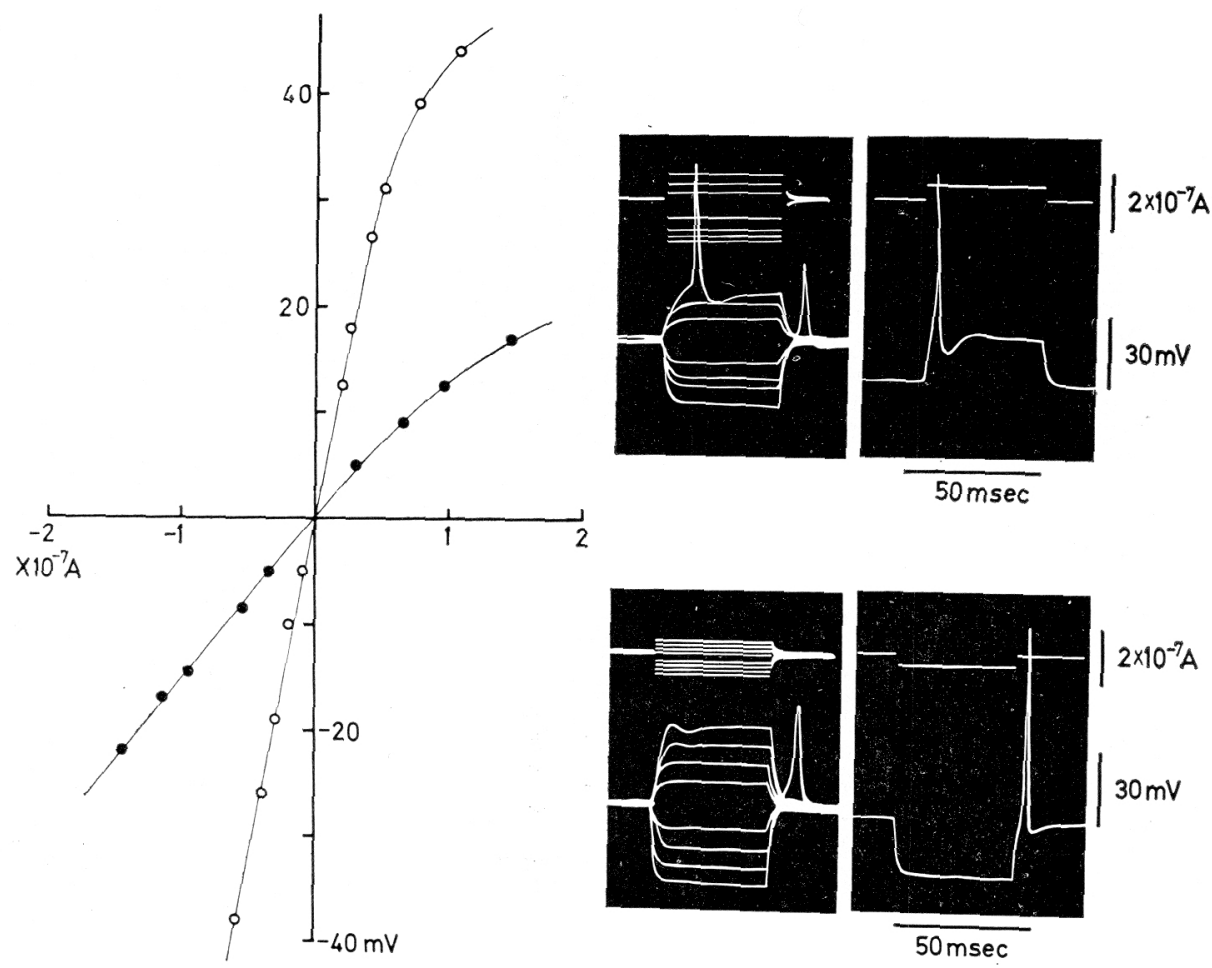

Fig. 5. Current-coltage $(\mathrm{I}-\mathrm{V})$ relationship of the membrane measured by the insertions of the two electrodes within $10 \mu$. Upper recordings: the type of the muscle fibre which had a lower membrane resistance. Lower recordings: the type of the muscle fibre which had a higher membrane resistance.

The type of muscle fibre which showed less rectifying property often produced graded responses to application of outward current pulses, while inward current pulses often generated anodal break excitation of the membrane. The spike amplitude produced as the off response was generally larger than that produc- 
ed by the outward current pulse. The muscle fibres which showed marked rectifying property of the membrane generated spikes with overshoot in response to outward current pulse.

The mean rates of rise and fall of the spikes with overshoot, elicited by the outward current pulses, were $340.6 \mathrm{~V} / \mathrm{sec}$ and $134.0 \mathrm{~V} / \mathrm{sec}$ respectively. The mean amplitude of the overshoot potential was $15.2 \mathrm{mV}(n=30)$.

The space constant of the muscle, $(\lambda)$, was obtained from the amplitudes of the electrotonic potentials measured at various distances from the stimulating partition. Figure 6 shows an example of the relationship between the amplitude of the electrotonic potential plotted on a logarithmic scale and the distance from the partition electrode. A linear relation could be observed. The space constant was $0.94 \mathrm{~mm}$ for this preparation. The mean value of the space constant was $0.72 \mathrm{~mm}(n=25)$. However, the histogram of the distribution of the space constant showed two modes $(0.94 \mathrm{~mm}$ and $0.60 \mathrm{~mm})$.
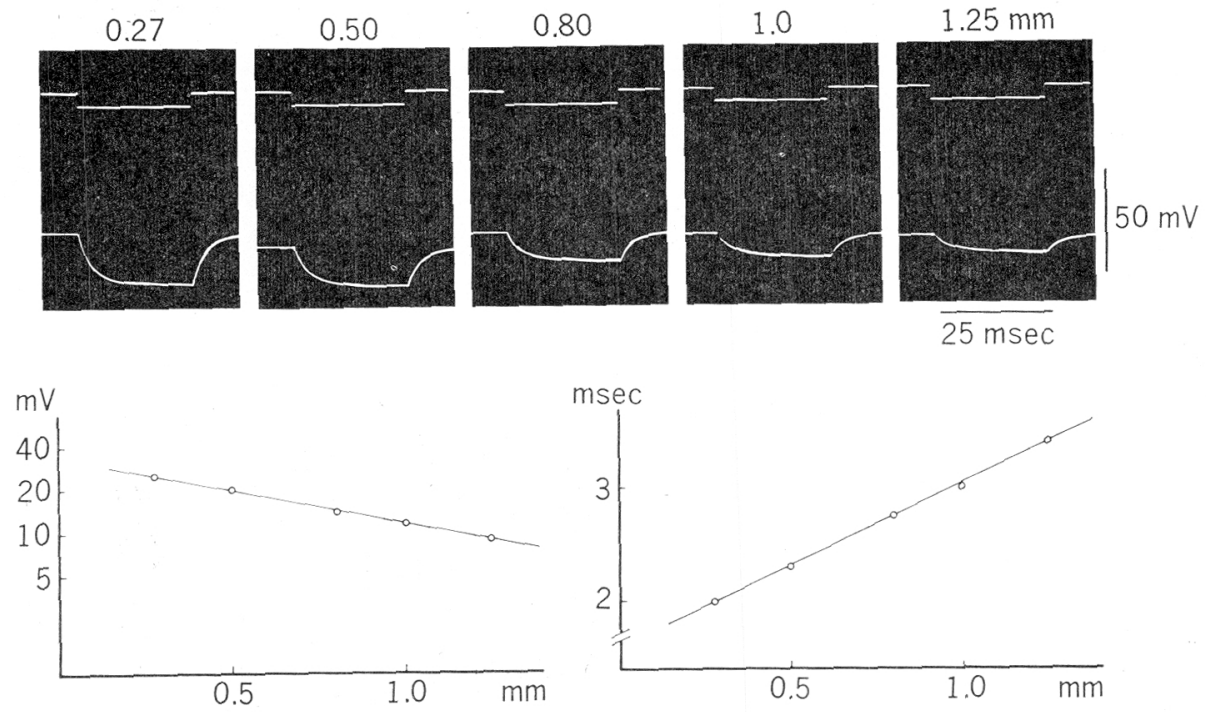

Fig. 6. The upper recordings show an example of decay of anodal electrotonic potentials along the fibre from the partition. Left graph shows the amplitude of the electrotonic potentials plotted on a logarithmic scale against the distance from the partition. Right graph shows the linear relationship between the time to half-maximum of the electrotonic potentials and the distance from the partition.

The time constant of the membrane $\left(\tau_{m}\right)$ could be measured by inserting two microelectrodes (for stimulating and recording) into the same muscle fibre, within $10 \mu$ of each other, the distance measured with the aid of a binocular microscope. The measured value was $4.2 \mathrm{msec}$ in the muscle with the low membrane resistance, and $4.6 \mathrm{msec}$ in the muscle with the high membrane resistance. 
The time constant of the membrane could also be calculated in four different ways from the experiments carried out by the partition method, assuming that the muscle fibres possess cable properties:

i) The relationship between the time to reach the half amplitude of the electrotonic potential and the distance from the stimulating electrode should be linear. The time constant of the membrane can be calculated from the slope, being equal to $\tau_{m} / 2 \lambda$. The calculated mean time constant of the membrane was $3.2 \mathrm{msec}$.

ii) Electrotonic potentials recorded at various distances from the partition electrode should fit the potential changes predicted theoretically when the calculated $\lambda$ and the most accurate value of the membrane time constant are inserted into the following equation:

$$
\begin{aligned}
V(x, t)=\frac{1}{2} V_{\substack{x=0 \\
t=\infty}}\left[e^{x / \lambda}\left\{1-\operatorname{erf}\left(\frac{x / \lambda}{2 \sqrt{t / \tau_{m}}}+\sqrt{t / \tau_{m}}\right)\right\}\right. \\
\left.+e^{-x / \lambda}\left\{1-\operatorname{erf}\left(\frac{x / \lambda}{2 \sqrt{t / \tau_{m}}}-\sqrt{t / \tau_{m}}\right)\right\}\right] .
\end{aligned}
$$

The mean value of the time constant of the membrane obtained in this way was $4.3 \mathrm{msec}$.

iii) The time constant of the membrane can be calculated from the conduction velocity of the excitation $(\theta)$, the time constant of the foot of the propagated spike, $\left(\tau_{f}\right)$, and the space constant, $(\lambda)$, from the following equation:

$$
2 \lambda^{2}=\tau_{f} \theta^{2}\left(\tau_{m}+\sqrt{\tau_{m}^{2}+\frac{4 \lambda^{2}}{\theta^{2}}}\right) .
$$

The time constant of the foot of the propagated spike was calculated from the graphic expression between the amplitude of the depolarization plotted on a logarithmic scale and the time after the onset of the depolarization. The mean value of the time constant of the foot of the propagated spike was $0.1 \mathrm{msec}(n=16)$. A typical example of the relation observed for the membrane depolarization and the time, and the actual propagated spike are shown in Fig. 7. The conduction velocity $(\theta)$ was measured from the latencies of the spikes at various distances from the stimulating electrode. The relationship between the latency after the onset of the stimulation and the distance from the stimulating electrode was linear, as shown in Fig. 8. The mean conduction velocity was $2.9 \pm 0.3 \mathrm{~m} / \mathrm{sec}(n=13)$. The calculated time constant of the membrane ranged between 0.95 and $0.32 \mathrm{msec}$ (mean value $0.5 \mathrm{msec}$ ).

iv) Finally, the time constant of the membrane can be obtained from the chronaxie of the muscle membrane for spike generation from the following equation:

$$
I=\frac{V}{R_{\text {eff }}} \cdot \frac{1}{\operatorname{erf} \sqrt{t / \tau_{m}}},
$$

where $I$ is the current intensity necessary to reach the threshold depolarization, 


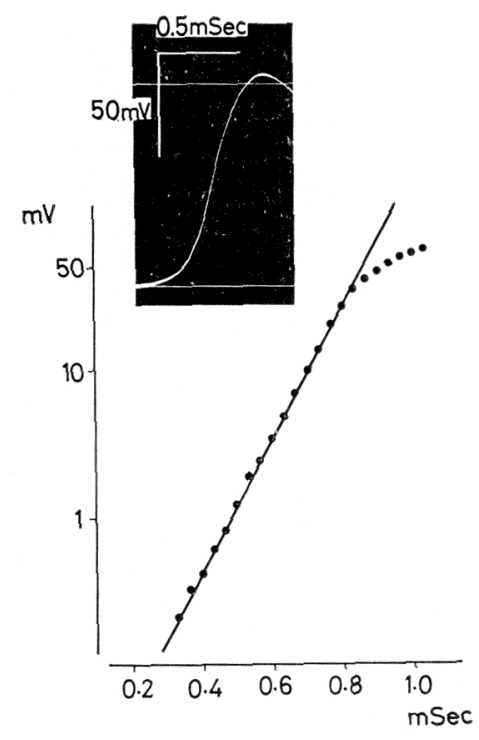

Fig. 7. Upper record shows the time course of the foot of the propagating spike. Lower graph shows the logarithmic plot of the foot of the spike against time.

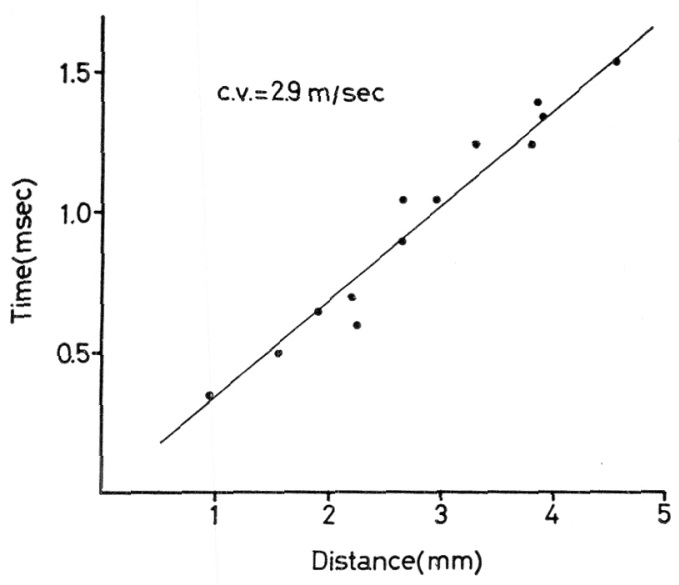

Fig. 8. Plot of the latency of the propagated spikes against the distance from the stimulating electrode.

$V$ is threshold membrane potential, $R_{\mathrm{efr}}$ is the effective membrane resistance, $\tau_{m}$ is the time constant of the membrane, and $t$ is the time for reaching to the threshold. The above equation could be abbreviated as follows:

$$
\text { chronaxie }=0.24 \tau_{m} .
$$

Figure 9 shows the relationship between the intensity and duration of the stimulus for the spike generation, the so-called I-D curve. The calculated mean chronaxie was $0.39 \pm 0.03 \mathrm{msec}, n=11$. The time constant of the membrane was, therefore, $1.6 \mathrm{msec}$.

The values of the time constant of the membrane calculated from the above four methods therefore differed. However, the values obtained from the methods described in (i) and (ii) were close to each other, and so also were those from the methods described in (iii) and (iv).

As shown in Table 2 and the results described above, there are two different types of muscle classified according to the membrane resistance. The muscle fibres with smaller membrane resistance had larger membrane capacitance $\left(C_{m}\right)$ than the muscle fibres with the higher membrane resistance. As a consequence, the time constant of the membrane in both the muscle fibres had nearly the same value. The muscle fibres of the two types could not be distinguished either from 
thier diameter or from their ability for spike generation. However, the muscle fibres with less marked rectifying property possessed larger effective membrane resistance, higher internal resistance and smaller membrane capacitance than the other type of muscle fibre.

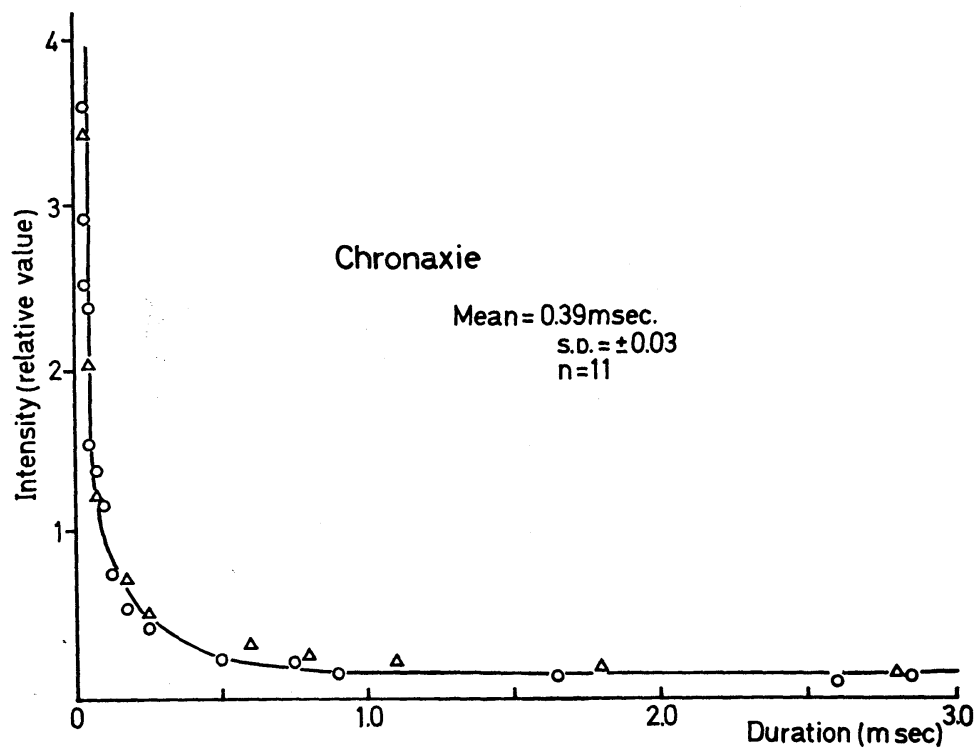

Fig. 9. The relationship between the intensity and duration of the stimulus for spike generation. Actual figure shows the results obtained from two preparations and the mean value was calculated from 11 preparations.

Excitation-contraction coupling and the mechanical properties of $M$. digastricus

The mechanical response of $M$. digastricus was evoked by electrical stimulation applied by the multigrid stimulating electrodes placed parallel with the longitudinal direction of the muscle. The duration of the contraction after the onset of stimulation to the whole tissue lasted less than $80 \mathrm{msec}$ and the rising phase of the contraction was terminated within $30 \mathrm{msec}$ at $25^{\circ} \mathrm{C}$. Figure 10 shows the relationship between the spike and tension recorded simultaneously from $M$. digastricus and $M$. semitendinosus. The latency for the tension development after the onset of the spike was $14 \mathrm{msec}$ at $25^{\circ} \mathrm{C}$ in $M$. digastricus.

Figure 11 shows the changes of the membrane potential and tension develop-

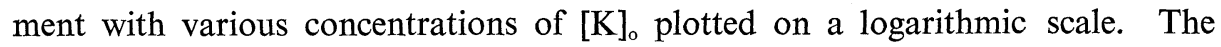
solutions with different concentrations of $[\mathrm{K}]$ o were prepared isotonically by reduction of $[\mathrm{Na}]_{0}$. Development of tension occurred when the membrane was depolarized to $-35 \mathrm{mV}$ in increased $[\mathrm{K}]_{\text {o }}$ solutions.

To compare the features of the tension development of $M$. digastricus with 


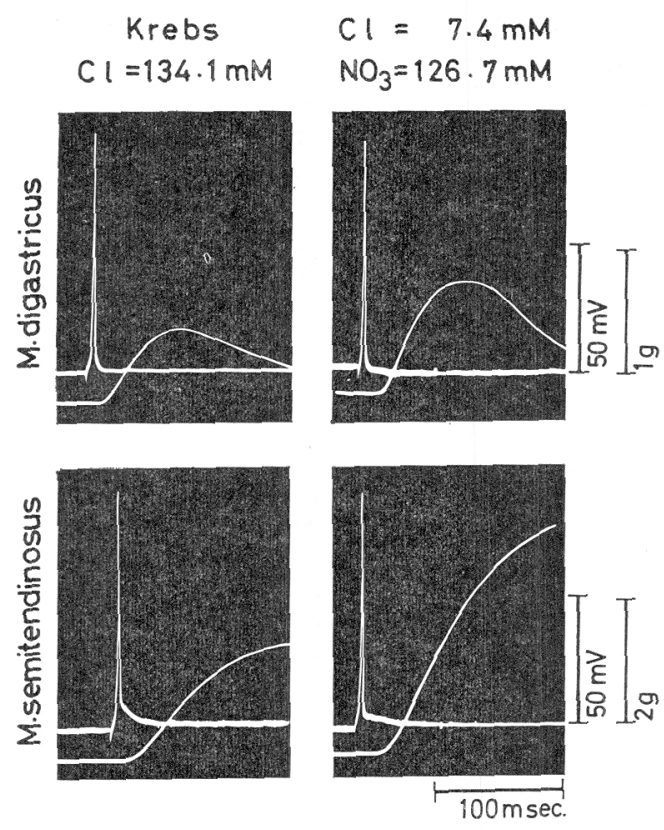

Fig. 10. Typical records of the relationship between the spike and tension. Left records: in normal Krebs solution. Right records: in the solution with nitrate ion substituted for chloride ion except calcium-chloride. Stimulus pluse duration: $0.5 \mathrm{msec}$.

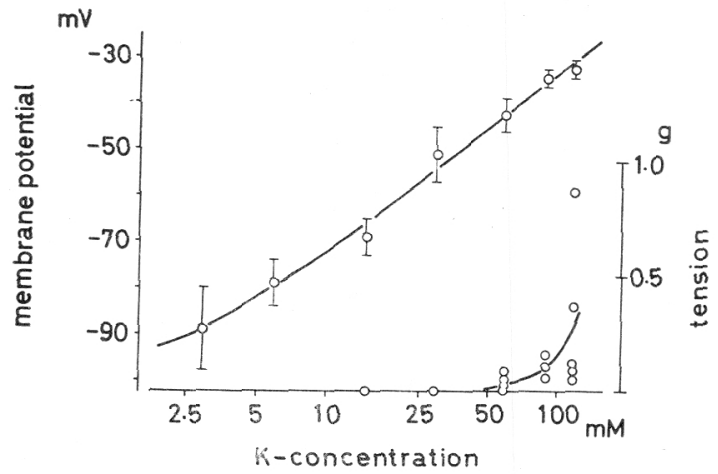

Fig. 11. The relationship between the change of membrane potential and the tension development with various external potassium concentrations plotted by the logarithmic scale.

another striated muscle in the guinea pig, M. semitendinosus was used. In Fig. 12 the records were superimposed photographically to show the tension development evoked by electrical stimulation at $25^{\circ} \mathrm{C}$. The maximum rate of rise of the contraction, the time to peak after the onset of tension development and the 
relaxation were much faster in $M$. digastricus (A) than in $M$. semitendinosus (B). In spite of this difference, the resting membrane potential and the spike amplitude of $M$. semitendinosus were nearly the same as those observed in $M$. digastricus (resting membrane potential $-81.2 \mathrm{mV}$ and spike amplitude $93 \mathrm{mV}$ in $M$. semitendinosus). These results might indicate that the sarcoplasmic reticulum is better developed in $M$. digastricus, or the release and reabsorption of $\mathrm{Ca}$ ion from and in to the reticulum system being possibly faster than in $M$. semitendinosus.

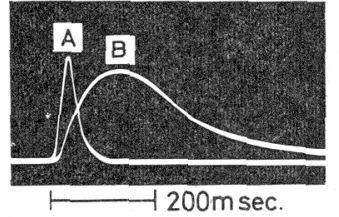

A

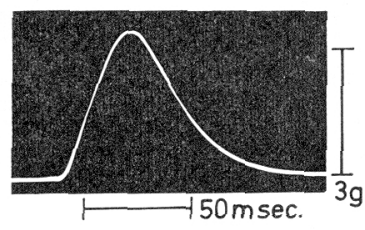

$A=M \cdot$ digastricus

$B=M \cdot$ semitendinosus

normal Krebs

$\mathrm{T}=25^{\circ} \mathrm{C}$

B

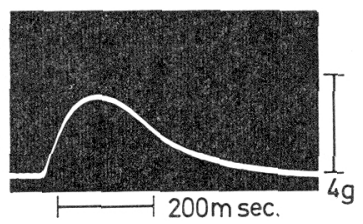

Fig. 12. The tension development of M. digastricus and M. semitendinosus.

Effects of caffeine and thymol on $M$. digastricus and $M$. semitendinosus were investigated to confirm the above hypothesis. Figure 13 shows the effects of caffeine at various concentrations $(1,5,10$ and $20 \mathrm{~mm})$ on the tension development of $M$. digastricus and $M$. semitendinosus. Caffeine potentiated the tension development when the concentration was increased to more than $1 \mathrm{~mm}$. Two clear differences on the effects of caffeine between $M$. digastricus and $M$. semitendinosus were observed. (i) In $M$. digastricus, the maximum rate of rise of the tension was not influenced, but the final tension development was increased, thus prolonging the time taken to reach the peak tension. On the other hand, in $M$. semitendinosus both the maximum rate of rise of the tension development and peak time were increased. (ii) In a concentration of $10 \mathrm{~mm}$, caffeine produced elevation of the resting tension in $M$. semitendinosus (caffeine contracture), but not in $M$. digastricus. When $20 \mathrm{~mm}$ caffeine was applied to $M$. digastricus, the amplitude of the tension was increased to 2.8 times that observed before the treatment.

The effects of thymol on the tension development of $M$. digastricus and $M$. semitendinosus differed from those of caffeine. Figure 14 shows typical effects of thymol $(0.5 \mathrm{~mm})$ and caffeine $(5 \mathrm{~mm})$ on the tension development. The records were taken before and after treatment with either caffeine or thymol, and 


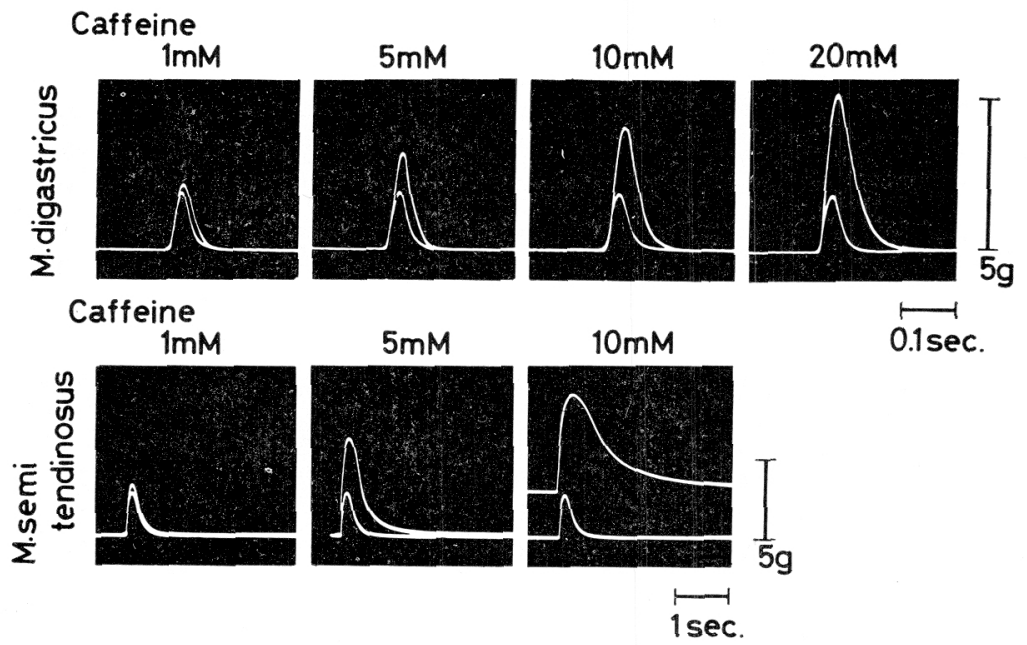

Fig. 13. The effects of caffeine on twitch and resting tension of $M$. digastricus and $M$. semitendinosus. Twitch tensions were elicited by electrical stimulation ( $5 \mathrm{msec}$ pulse). The tensions recorded before and after treatment with drugs were photographically superimposed.
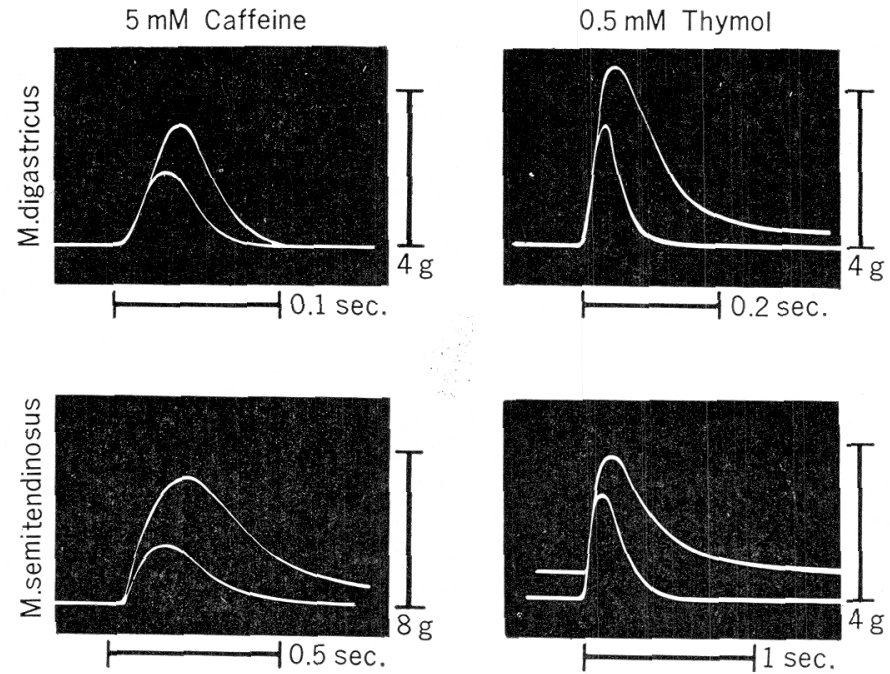

Fig. 14. The effects of caffeine and thymol on twitch and resting tension of $M$. digastricus and $M$. semitendinosus. The recording methods were the same with described in Fig. 13.

were superimposed photographically to compare the rising velocity, falling velocity and peak tension of the twitch in the two conditions. As described previously, caffeine ( $5 \mathrm{~mm}$ ) enhanced the rate of rise of the tension in $M$. semitendinosus but not in $M$. digastricus. However, $0.5 \mathrm{~mm}$ thymol did not enhance the rate of rise 
of tension in either of the muscles, but thymol at only $0.5 \mathrm{~mm}$ increased the resting tension (thymol contracture) in $M$. semitendinosus. These results might indicate that caffeine enhances the amount of $\mathrm{Ca}$ ion released from the reticulum in both the tissues and also the rate of release of $\mathrm{Ca}$ ion in the case of $M$. semitendinosus. On the other hand, thymol might suppress the reabsorption of $\mathrm{Ca}$ ion in to the reticulum. These results might confirm the above hypothesis that the sarcoplasmic reticulum of $M$. digastricus is better developed, and therefore caffeine may have less effect on the rate of rise in tension.

\section{DISCUSSION}

Passive electrical properties of the membrane. Two types of muscle fibre in $M$. digastricus could be distinguished from their electrical properties, i.e. one type of muscle fibre had a high membrane resistance $\left(1,300 \Omega \mathrm{cm}^{2}\right)$, small membrane capacity $\left(3.6 \mu \mathrm{F} / \mathrm{cm}^{2}\right)$ and lesser rectifying property compared with the other type of muscle fibre ( $330 \Omega \mathrm{cm}^{2}$ and $12.8 \mu \mathrm{F} / \mathrm{cm}^{2}$ respectively). However, the length constant and the time constant of the membrane had roughly the same values in both types of muscle.

The rectifying properties of muscle are thought, from the constant field equations, to be due to changes in either the ionic permeability coefficient during displacements of the membrane potential level or in the ionic conductance, without changes of the permeability coefficient (HodgKin, HuXley and Katz, 1952; KATZ, 1948; Adrian and FreYGANG, 1962). The slow muscle fibre of frog possessed more dominant rectifying properties than fast muscle fibres (KATZ, 1948; Adrian and PeACHeY, 1965). The experiments in this study experiments indicate that the muscle fibres with high membrane resistance had a higher threshold for the production of the rectifying property by the displacement of the membrane potential than those with low membrane resistance. Presumably Kconductance of the membrane might differ in the two types of muscle.

In these experiments, the results obtained from $M$. digastricus were insufficient to classify the muscle into slow or fast type, since electron microscopy of the muscle fibre did not indicate any distinct difference within the muscle fibres of the arrangements of the contractile protein, Z-line, sarcoplasmic reticulum and tubular structure (Adrian and Peachey, 1965; Peachey, 1965). Moreover, both muscle fibre types showed propagated spikes.

The membrane time constant calculated by different methods based on the cable equations showed two different values, i.e. the time constant of the membrane calculated from the method described in the results (i) and (ii) is larger than that calculated from the method described in (iii) and (iv). The time constant calculated from the equations involving the propagated spike had a smaller value than that calculated from only the passive membrane properties. These differences 
in the value for the time constant of the membrane might indicate that the membrane time constant is composed of two different components, i.e. one component is related to the propagation of the excitation and the other component is presumably related to the tubular system, as was suggested for the frog twitch muscle fibre and mammalian cardiac muscle fibre (FAlK and Fatt, 1964; Adrian and Peachey, 1965; Fozzard, 1967; Sakamoto, 1969; Weidman, 1970). On the other hand, Hidaka and ToIDA (1969) concluded that the membrane capacitance and resistance in the red and white muscles of silver carp corresponded with those in the slow and fast muscles of frog, although no differences in the structure of the two types of the muscle were recognized in the case of the silver carp. In my experiments, the structural specificity of $M$. digastricus could not be classified into these two different types. Further study is required to investigate the relationship between the structure and the electrical properties of the membrane of the M. digastricus.

Changes in the resting membrane potential in various $[\mathrm{K}]_{0}$ indicated that the membrane potential was mainly governed by the difference in intracellular and extracellular $[\mathrm{K}]_{\text {o. }}$ However, the Na-permeability might also influence the membrane potential when the $[\mathrm{K}]_{\circ}$ is near the normal concentration, since the linear relationship between the membrane potential and $[\mathrm{K}]_{\text {o }}$ no longer held in these conditions (below $20 \mathrm{~mm}$ of $[\mathrm{K}]_{\mathrm{o}}$ in solution II and $10 \mathrm{~mm}$ in solution I). The $\mathrm{Cl}$-distribution seems to be passive, because when $\mathrm{Cl}$ ion was replaced with foreign anions, the membrane potential remained the same as before the replacement. Furthermore, when the solutions with excess $\mathrm{K}$ ion were prepared sot hat $[\mathrm{K}]_{\circ} \times$

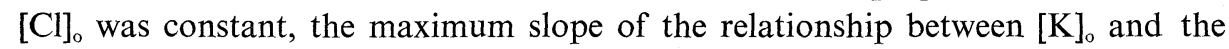
membrane potential was close to the slope expected from the concentration gradients of the $\mathrm{K}$-ion according to the Nernst equation.

Mechanical properties and excitation-contraction coupling of $M$. digastricus. To compare the mechanical responses of $M$. digastricus with other muscles of the guinea pig, M. semitendinosus was used. The rising and falling phase of contractions were much shorter in $M$. digastricus than in $M$. semitendinosus after field stimulation applied by the multigrid stimulating electrodes. The mechanical response of $M$. digastricus was also evoked by depolarization of the muscle membrane by increase of $[\mathrm{K}]_{0}$. The critical membrane potential for evoking tension development was about $-35 \mathrm{mV}$, and this value was higher than that in frog striated muscle $(-50 \mathrm{mV})$ and crustacean muscle $(-60 \mathrm{mV})$ (HodGKIN and Horowicz, 1970; SANDow, 1965; MAShima and MATsumura, 1962). The relationship between the threshold potential and tension development shifted in a less depolarized direction when the $\mathrm{Cl}$ ion of the Krebs solution was replaced with SCN ion. The critical membrane potential for evoking tension development was $-65 \mathrm{mV}$ in Krebs solution with $50 \%$ replacement of $\mathrm{Cl}$ by SCN ion. These facts indicate the importance of anion permeability for excitation-contraction coupling in muscles. Whether the potentiation of the twitch tension and the reduction of the mechanical threshold by replacement of $\mathrm{Cl}$ ion by other anions is due to re- 
duction of $\mathrm{Cl}$ ion in the myoplasm or to the effects of foreign anions on the relaxing factor should be studied further.

Repetitive stimulation of $M$. digastricus evoked tetanic tension development, although the stimulus frequency necessary to evoke tetanic contraction was higher in $M$. digastricus than in $M$. semitendinosus. When a stimulus frequency evoking incomplete tetanus was applied to the tissue, the amplitude of the peak tension was gradually lowered in $M$. digastricus instead of increasing, as in $M$. semitendinosus (Y. Yamamoto, personal communications).

To clarify the differences in the muscle properties of these two muscles, the effects of caffeine and thymol were tested, as demonstrated in the frog muscle fibre by EBASHI and ENDO, 1968. It was concluded that caffeine mainly accelerated the release of $\mathrm{Ca}$ ion from the sarcoplasmic reticulum, while thymol inhibited the reabsorption of $\mathrm{Ca}$ ion in to the sarcoplasmic reticulum. As a consequence, both the drugs enhanced the amplitude of tension development (EBASHI and ENDO, 1968; SANDOw, 1965). The different responses of the muscles might indicate qualitative differences in the properties of the sarcoplasmic reticulum. The results suggested that the sarcoplasmic reticulum in $M$. digastricus was well developed, and presumably release and reabsorption of $\mathrm{Ca}$ ion from and in to the reticulum are fast. Therefore, caffeine might not further accelerate the rate of rise of the tension development, but might prolong the time taken to reach the peak. On the other hand, thymol might suppress the reabsorption of $\mathrm{Ca}$ ion, thereby enhancing the amplitude and prolonging the falling phase of the tension development.

When the effects of caffeine and thymol on $M$. digastricus were compared with those on $M$. semitendinosus, the sarcoplasmic reticulum was thought to be less developed in $M$. semitendinosus, because caffeine enhanced the rate of rise and peak amplitude of the tension, presumably due to enhancement of $\mathrm{Ca}$ ion release, and because thymol enhanced the peak amplitude and relaxation time, presumably due to inhibition of reabsorption of $\mathrm{Ca}$ ion in to the reticulum. The electron microscopy observations might explain the above phenomena, since the two triads including tubular structures appeared within one sarcomere in M. digastricus. These morphological features of the muscle might modify its responses to electrical and chemical stimulation.

The auther is grateful to Dr. H. Nishihara, Department of Anatomy, Faculty of Medicine, Kyushu University, for preparing electron micrographs.

\section{REFERENCES}

Abe, Y. and Tomita, T. (1968) Cable properties of smooth muscle. J. Physiol., 196: 87.

Adrian, R. H. and Freygang, W. H. (1962) The potassium and chloride conductance of frog muscle membrane. J. Physiol., 163: 61.

Adrian, R. H. and Peachey, L. D. (1965) The membrane capacity of frog twitch and slow muscle fibres. J. Physiol., 181: 324.

Albuquerque, E. X. and TheslefF, S. (1968) A comparative study of membrane properties of 
innervated and chronically denervated fast and slow skeletal muscles of the rat. Acta Physiol. Scand., 73: 471.

Anderson, D. J. (1967) Mastication. In Handbook of Physiology, Sec. 6, Alimentary Canal, Vol. IV, Motility, American Physiological Society, Washington, 1811-1819.

Boyd, I. A. and Martin, A. R. (1959) Membrane constants of mammalian muscle fibres. $J$. Physiol., 147: 450.

Desmedt, J. É. (1959) The physio-pathology of neuromuscular transmission and the trophic influence of motor innervation. Am. J. Physic. Med., 38: 248.

Ebashi, S. and Endo, M. (1968) Calcium ion and muscle contraction. In Progress in Biophysics and Molecular Biology, ed. by Butler, J. A. V. and Noble, D. Pergamon Press, Oxford and New York, 123-183.

FALK, G. and FATT, P. (1964) Linear electrical properties of striated muscle fibres observed with intracellular electrodes. Proc. Roy. Soc. B., 160: 69.

Fozzard, H. A. (1966) Membrane capacity of the cardiac purkinje fibre. J. Physiol., 182: 255.

Hidaka, T. and ToIdA, N. (1969) Biophysical and mechanical properties of red and white muscle fibres in fish. J. Physiol., 201: 49.

Hodgkin, A. L., Huxley, A. F. and Katz, B. (1952) Measurements of current-voltage relations in the membrane of the giant axon of Loligo. J. Physiol., 116: 424.

Hodgkin, A. L. and Horowicz, P. (1959) The influence of potassium and chloride ions on the membrane potential of single muscle fibres. J. Physiol., 148: 127.

Hodgkin, A. L. and Horowicz, P. (1960a) The effect of sudden changes in ionic concentrations on the membrane potential of single muscle fibres. J. Physiol., 153: 370 .

Hodgkin, A. L. and Horowicz, P. (1960b) Potassium contractures in single muscle fibres. J. Physiol., 153: 386.

Hodgkin, A. L. and Horowicz, P. (1960c) The effect of nitrate and other anions on the mechanical response of single muscle fibres. J. Physiol., 153: 404.

KATz, B. (1948) The electrical properties of the muscle fibre membrane. Proc. Roy. Soc. B., 135: 506.

Kawamura, Y. and Fujimoto, S. (1958) A study of the jaw opening reflex. Med. J. Osaka Univ., 9: 377.

KiyohaRA, T. and SAto, M. (1967) Membrane constants of red and white muscle fibres in the rat. Jap. J. Physiol., 17: 720 .

Mashima, H. and Matsumura, M. (1962) Roles of external ions in the excitation-contraction coupling of frog skeletal muscle. Jap. J. Physiol., 12: 639.

ORKAND, R. K. (1961) The relation between membrane potential and contraction in single crayfish muscle fibres. J. Physiol., 161: 143.

Peachey, L. D. (1965) The sarcoplasmic reticulum and transverse tubles of the frog's sartorius. J. Cell Biol., 25: 209.

SAкамото, Y. (1969) Membrane characteristics of the canine papillary muscle fiber. J. Gen. Physiol., 54: 765.

SANDow, A. (1965) Excitation-contraction coupling in skeletal muscle. Pharmacol. Rev., 17: 265.

Stefani, E. and Steinbach, A. B. (1969) Resting potential and electrical properties of frog slow muscle fibres. Effect of different external solutions. J. Physiol., 203: 383.

Weidman, S. (1970) Electrical constants of trabecular muscle from mammalian heart. $J$. Physiol., 210: 104. 